\title{
Disparities in Early Mortality among Chronic Kidney Disease patients who Transition to Peritoneal Dialysis and Hemodialysis with and without Catheters
}

\author{
John J. Sim, MD¹, Hui Zhou², Jiaxiao Shi², Sally F. Shaw ${ }^{2}$, Shayna L. Henry², Csaba P. \\ Kovesdy ${ }^{3}$, Kamyar Kalantar-Zadeh ${ }^{4}$, and Steven J. Jacobsen ${ }^{2}$ \\ ${ }^{1}$ Division of Nephrology and Hypertension, Kaiser Permanente Los Angeles Medical Center, Los \\ Angeles, CA USA \\ ${ }^{2}$ Department of Research and Evaluation, Kaiser Permanente Southern California, Pasadena, CA \\ USA \\ ${ }^{3}$ Division of Nephrology, University of Tennessee Health Science Center, Memphis, TN, USA \\ ${ }^{4}$ Division of Nephrology and Hypertension, University of California Irvine Medical Center, Irvine, \\ CA USA
}

\section{Abstract}

Purpose-The early period after chronic kidney disease (CKD) patients transition to end stage renal disease (ESRD) represents the highest mortality risk but is variable among different patient populations and clinical circumstances. We compared early mortality outcomes among a diverse CKD population that transitioned to ESRD.

\begin{abstract}
Methods-A retrospective cohort study (1/1/2002 through 12/31/2013) of CKD patients (age>/ $=18$ years) who transitioned to peritoneal dialysis (PD), hemodialysis (HD) with arteriovenous fistula/grafts, and HD with catheters was peformed. Multivariable cox regression modeling used to estimate 6-month all-cause mortality hazard ratios (HR) among the 3 treatment groups after adjustment for patient and clinical characteristics.
\end{abstract}

Results-Among 5,373 ESRD patients (62.7 years, 41.3\% females, 37.5\% Hispanics, 13.3\% PD, $34.9 \%$ HD with fistula/graft, $51.8 \%$ HD with catheter), 551 (10.3\%) died at 6 months. Mortality rates were highest immediately after transition (299 deaths-per-1000 person-years in first month). Compared to PD patients, the 6-month mortality HR (95\% CI) was 1.87 (1.06-3.30) in HD with fistula/graft patients and 3.77 (2.17-6.57) in HD with catheter patients. Inpatient transition (HR

Correspondence: John J. Sim, MD, Division of Nephrology and Hypertension, Kaiser Permanente Los Angeles Medical Center, 4700 Sunset BI, Los Angeles, CA 90027 USA, John.i.sim@kp.org.

Contributions: Research area and study design: JJS, SJJ; Data Acquisition: HZ, JS; Analysis or interpretation of data: JJS, SJJ, HZ, JS, KKZ, CPK; Study supervision: JJS, SJJ; Statistical analysis: HZ; Drafting of the manuscript: JJS; Critical revision of the manuscript for important intellectual content: SJJ, HZ, SFS, KKZ, CPK, SH, JS; Administrative, technical, or material support: SFS, SJJ.

Each author contributed important intellectual content during the manuscript drafting or revision and accepts accountability of the overall work by ensuring that questions pertaining to the accuracy or integrity of any portion of the work are appropriately investigated and resolved. JJS takes responsibility that this study has been reported honestly, accurately, and transparently; that no important aspects of the study have been omitted, and that any discrepancies from the study as planned have been explained.

None of the authors have any conflicts of interest relevant to this manuscript. 
1.32), acute kidney injury (HR 2.06), and an eGFR $>/=15$ vs $5-9$ (HR 1.68) at transition were also associated with higher early mortality risk.

Conclusion-Among a diverse CKD population who transitioned to ESRD, we observed considerable differences in early mortality risk among PD, HD with fistula/graft, and HD with catheter patients. The identification of patient specific and clinical environmental factors related to high early mortality may provide insights for managing advanced stages of CKD and shared decision making.

\section{Keywords}

mortality; end stage renal disease transition; chronic kidney disease; epidemiology; comparative outcomes

\section{Introduction}

While the end stage renal disease (ESRD) population itself experiences high mortality, the early period after transition to ESRD appears to be most vulnerable. High mortality rates of up to $30 \%$ have been described within the first year of transition from chronic kidney disease (CKD) to ESRD [1-6]. While the evidence is not entirely consistent, studies have described a mortality spike within the first few weeks to months of ESRD transition while others have not $[7,3,8,9]$. This alarmingly high rate of mortality has been the impetus to one of the Healthy People 2020 goals to reduce ESRD mortality to 329 deaths per 1000 patient years at risk within the first 3 months of ESRD transition[10].

A better understanding of the late CKD and early ESRD populations could provide insight into the reasons for this high transition mortality. It could have important implications for prognostication and help guide management strategies and shared decision making. An important consideration is to identify the patients that pose risk for early mortality as they may represent a different populations and circumstances altogether. The identification of these populations earlier in the course of CKD could help inform treatment plans and manage expectations through shared decision making.

Currently, there are limitations to available information on late stage CKD and early ESRD outcomes. Large data registries such as the United States Renal Data System (USRDS) historically have not comprehensively captured the early period after transition, due to a 3month gap or an ascertainment bias[11,2]. Medicare coverage does not go into effect until 90 days after start of ESRD for those without existing Medicare including those under age 65 years without disabilities [3]. This lag period can contribute to an under-ascertainment of ESRD patients in the United States[2]. In addition, late stage CKD cohort studies often pool information from different data sources and clinical care environments, potentially limiting the interpretation of findings $[12,13]$. Thus the ideal management strategies prior to and at the initiation of renal replacement continues to evolve.

We hypothesize that early dialysis mortality is affected by the circumstances at transition from CKD to ESRD. These factors may include the timing, clinical setting and events preceding dialysis, and ultimately the dialysis modality itself which may be manifestation a 
pre-ESRD care. In this USRDS special center study[14,1], we identified a large diverse CKD population that transitioned to ESRD from a single integrated health system with comprehensive electronic health records (EHR). Among patients who started peritoneal dialysis (PD), hemodialysis (HD) with a fistula/graft (AVF/AVG), and HD with a catheter, we sought to compare 6-month mortality risk and determine risk factors for early ESRD mortality.

\section{Methods}

KPSC is an integrated health system geographically located in southern California and comprised of 15 medical centers and over 200 satellite medical office buildings. Members have similar coverage benefits including co pays for visits and medications. This study was approved by the KPSC institutional review board and exempted from informed consent (IRB \#10591).

\section{Study population}

The study population was comprised of KPSC adults age 18 years and older who had CKD that transitioned to ESRD between January, 2002 through March, 2015 and had at least one estimated glomerular filtration (eGFR) measurement within 90 days before transition. CKD was defined as 2 separate eGFR $<45 \mathrm{ml} / \mathrm{min} / 1.73 \mathrm{~m}^{2}$ that were 90 days or more apart. eGFR $<45 \mathrm{ml} / \mathrm{min} / 1.73 \mathrm{~m}^{2}$ was chosen as the inclusion criteria for the CKD cohort because of the higher risk for ESRD in this population regardless of proteinuria[15]. The eGFR was calculated using the Chronic Kidney Disease Epidemiology Collaboration (CKD-EPI) equation[16]. ESRD was defined as treatment with HD (in center, home, or nocturnal) and PD. Patients who underwent preemptive renal transplantation were excluded.

All health information is collected as part of routine clinical care in a shared EHR. Study information on demographics, vitals, co morbidities, medications, and outcomes were extracted from the EHR and KPSC regional quality information data sources. The KPSC Renal Business Group captures and tracks all patients who initiated renal replacement therapy at an outpatient dialysis center or received a renal transplant. It also maintains a patient registry of all adult KPSC members who meet criteria for CKD [17]. Patient characteristics including vital signs, demographics, and laboratory results within 90 days prior to ESRD transition were extracted from the EHR. Comorbidity information was retrieved from the EHR using the International Classification of Diseases (ICD) codes. The cause of ESRD was extracted from the internal KPSC Renal Business Group records which was derived from clinician assessment and documentation by the physicians. Information on type of HD access used at the start of HD (AVF/AVG, or vascular catheter], setting of first ESRD (inpatient vs outpatient start), and acute kidney injury (based on ICD codes) within 90 days before ESRD transition were also extracted. Patients were categorized based on ESRD treatment types (PD, HD with AVF/AVG, or HD with catheter), age in years (>80, 70-79, 60-69, <60), and pre-ESRD transition eGFR. Patients were passively followed through the EHR for up to 6 months after ESRD transition. 


\section{Outcomes}

The primary outcome evaluated was early all-cause mortality as defined as within 6 months after transition to ESRD. Mortality information was obtained from the KPSC Mortality database which combines information from seven data sources, including California State Death Master Files, California State Multiple Cause of Death Master Files, Social Security Administration Death Master Files, KPSC Hospital and Emergency Room records, KPSC Membership System, Perinatal Data Mart, and Outside Claims Processing System. Mortality rates were calculated for each month following ESRD transition up to 6 months and reported as events per 1000 patient years. Patients were followed until a mortality outcome occurred, until 6 months of follow up after ESRD, or until the end of the study observation period (March, 2015). Because mortality information was captured from KPSC and California state files, we did not censor any patients who lost membership or left the health plan. Despite the fact that ESRD patients may switch modalities or receive renal transplantation within the 6 months after ESRD transition, we analyzed our variables at the time of ESRD similar to an "intention to treat" approach.

\section{Statistical Analysis}

Patient characteristics were compared across the 3 ESRD treatment types. Categorical variables were presented as counts (frequencies), and continuous variables were presented as means (standard deviation). $\chi^{2}$ test was performed to compare independent categorical variables, and ANOVA was used to test the difference of continuous variables. Mortality rates were compared by treatment type (PD, HD with AVF/AVG, HD with catheter), prelude (pre-ESRD transition) eGFR, and age categories. The primary analysis was 6-month mortality risk after transition to ESRD using Cox proportional hazards modeling. 6-month HR's were estimated for ESRD treatment type. Multivariable hazard ratios (HR) were estimated adjusting for age, sex, race/ethnicity, comorbidities DM and heart failure, transition setting (inpatient or outpatient, acute kidney injury, and prelude laboratory values, including eGFR. We tested proportional assumption by introducing the interactions between exposure variables and time. No indication of proportionality violation was found. This was also confirmed by Supremum Test for Proportional Hazards. All hypothesis tests were 2sided with a significance level of $\mathrm{p}<0.05$. Statistical analysis was conducted using SAS Enterprise Guide 5.1 (SAS Institute, Cary, NC).

\section{Results}

Among 71,127 individuals identified with CKD between 2002-2013, a total of 5,819 (8.2\%) transitioned to ESRD before March, 2015. The study cohort was comprised of 5,373 CKD patients who transitioned to ESRD, had a documented eGFR within 90 days pre-transition, and had an ESRD modality identified (Figure 1). The mean age was 62.7 years with $41.3 \%$ females, 37.5\% Hispanics, $27.7 \%$ non-Hispanic whites, $22.7 \%$ blacks, and 9.8\% Asians. The cause of ESRD were DM (69.1\%), hypertension (12.9\%), glomerulonephritis (5.8\%) and other (12.2\%). Overall, DM was identified in $79.1 \%$ and listed as the primary cause of ESRD for $69.1 \%$ of the study cohort. A total of 2,266 (42.2\%) patients had acute kidney injury within 90 days before ESRD transition (Table 1). The median hemoglobin level was $10.2 \mathrm{~g} / \mathrm{L}$ and $26.4 \%$ had a serum $\mathrm{CO}_{2}$ measurement under $20 \mathrm{mEq} / \mathrm{L}$ (Table 1). 
Within the study cohort, 714 (13.3\%) patients transitioned to PD, 1,874 (34.9\%) patients transitioned to HD with AVF/AVG, and 2,785 (51.8\%) patients transitioned to HD with a catheter. There were 1,915 (35.6\%) patients who transitioned to ESRD in an inpatient setting (40.7\% of HD patients and $2.5 \%$ of PD patients). Arteriovenous grafts were present in $4 \%$ of the total study cohort. The majority of the cohort transitioned to ESRD with an eGFR in the range of $5-14 \mathrm{~mL} / \mathrm{min} / 1.73 \mathrm{~m}^{2}$.

\section{Mortality}

At 6 months following transition to ESRD, 551 (patients had died (14 PD, $97 \mathrm{HD}$ with AVF/ AVG, and $440 \mathrm{HD}$ with a catheter). Mortality rates were highest immediately (within month 1) after transition and then declined (Figure 2A). Mortality rates were 299 (deaths per 1000 person-years) at month 1 and then declined to 224 by month 3 (Figure 2A). This trend was mostly observed among the HD population but not among PD patients (Figure 2B). Patients with a HD catheter had higher early mortality compared to HD patients who transitioned with an AVF/AVG. Higher early mortality was also observed in those who transitioned with eGFR $\geq 15 \mathrm{~mL} / \mathrm{min} / 1.73 \mathrm{~m}^{2}$ and in older patients (Figures $2 \mathrm{C} / \mathrm{D}$ ).

\section{Regression Analyses for Early ESRD Mortality}

Compared to patients who transitioned to PD, the fully adjusted 6-month mortality HR's $(95 \% \mathrm{CI})$ were 1.87 (1.06-3.30) and 3.77 (2.17-6.57) for HD with AVF/AVG and HD with a catheter, respectively (Table 2). There was no difference in mortality risk between males and females. Older age demonstrated an incremental pattern of higher mortality risk with age $\geq 80$ years having a 6-month HR of 4.19 (3.14-5.59) compared to age $<60$ years. Non- Hispanic whites had worse survival compared to Hispanics, Asians, and blacks. Pre-ESRD transition eGFR <5, 10-14, and $\geq 15 \mathrm{ml} / \mathrm{min} / 1.73 \mathrm{~m}^{2}$ had 6-month mortality HR's of 1.04 (0.69-1.58), 1.38 (1.11-1.73), and 1.68 (1.34-2.11) respectively compared to eGFR $5-9 \mathrm{ml} / \mathrm{min} / 1.73 \mathrm{~m}^{2}$. Heart failure or $\mathrm{CO}_{2}<20 \mathrm{mEq} / \mathrm{L}$ were not associated with higher early mortality risk. Overall, having DM had a lower 6-month mortality HR [0.67 (0.55-0.81)] within our study population (Supplemental Table 1). The circumstances around the transition appeared to affect early mortality. Patients who transitioned to ESRD in the hospital (inpatient) had a HR of 1.32 (1.11-1.58) compared to those who started dialysis on an outpatient basis. Patients diagnosed with acute kidney injury within 90 days prior to ESRD had a 6-month HR of 2.06 (1.66-2.54) (Supplemental Table 1).

Sensitivity analyses using cause of ESRD in the multivariable modeling demonstrated 6month mortality HR's of 1.96 (1.11-3.46) and 4.62 (2.67-8.00) for HD with AVG/AVF and HD with a catheter, respectively compared to PD (Supplemental Table 1).

\section{Discussion}

We evaluated early ESRD mortality in 5,373 CKD patients who transitioned to dialysis among 3 different treatment types (PD, HD with an AVF/AVFG, and HD with a catheter) and found that PD patients had the lowest risk for early mortality. Compared to PD patients, HD patients had a two to four-fold higher 6-month mortality risk depending on the type of access used at ESRD transition. Early mortality was also associated with patients who 
started dialysis at a higher eGFR, who were older, and who endured more acute circumstances prior to ESRD transition. The highest mortality was manifested within the first month. Our findings from a real world clinical care environment demonstrate that the period immediately after ESRD represents the most vulnerable stage for CKD patients transitioning to ESRD.

These insights into the high mortality in early ESRD could have important implications for both prognostication and management purposes. Catheter use, volume overload, infrequent CKD care, and perhaps rapid eGFR decline emphasizes the importance of pre-ESRD transition care[18-21]. Early initiation of dialysis, however, does not seem to be associated with ESRD survival[22,23]. By contrast, earlier ESRD transition may even be associated with worse outcomes[24,23]. Although confounding by clinical indication make affect the assessment, we similarly observed that patients who transitioned with eGFR $15 \mathrm{~mL} / \mathrm{min} / \mathrm{m}^{2}$ or greater experienced the highest early mortality.

The high rates of mortality immediately after ESRD were mostly accounted for by the HD with catheter population. Our findings were similar to prior observations that demonstrated that HD patients with catheters had higher mortality compared to HD with AVF/ AVG[25,20,26]. The HD with AVF/AVG population also demonstrated a higher mortality rate immediately after ESRD transition, though not as pronounced as the catheter population. Conversely, the PD population appeared to have stable monthly mortality rates for the first 6 months after ESRD transition. The improved short-term outcomes in PD vs HD appear consistent with prior observations that compared dialysis modalities[27-29].

Our findings underscore the need to recognize the differences in patient characteristics and clinical circumstances among patients that transition to ESRD. These patient specific, clinical environment-related, and treatment-related influences may help identify more optimal management strategies prior to and at the initiation of renal replacement. Unfortunately, there remains questions about the ideal management strategies in terms of blood pressure, DM, CKD-Mineral Bone Disorders (CKD-MBD), and anemia management strategies. The real world clinical care and outcomes among a large diverse ESRD transition population could help provide additional and important insights.

In addition, the recognition of patients who are at highest risk for early mortality has potential benefit[30,9]. The subgroup that experiences early mortality appears to represent a different population (or populations) altogether. More aggressive and timely management strategies such as earlier and more frequent nephrology care may be beneficial[21]. Conversely, the elderly and patients with high comorbidity burdens may have shortened life expectancies regardless of whether they receive dialysis [31,32]. These represent populations/situations in which renal replacement may not improve or extend lifespan. The information may improve shared decision-making discussions which might more easily include conservative care of ESRD without dialysis as a viable option. With hundreds of thousands of people transitioning to ESRD throughout the world on an annual basis[33], the instances in which ESRD treatment and expenditures are futile and dialysis may not affect or prolong survival are of great concern. One potentially modifiable risk factor we observed was that patients with acidemia $(C O<20)$ at ESRD transition had higher early mortality risk. 
Perhaps earlier and improved management of acidemia may lead to better survival during the early period after starting dialysis.

The information from our integrated health system captures early mortality events more comprehensively and accurately than traditional USRDS data sources[11,2]. As Medicare coverage does not go into effect until 90 days after start of ESRD for those without existing Medicare coverage including those under age 65 years without disabilities who experience early mortality. This accounts for up to $60 \%$ of patients who transition to ESRD[3]. By definition, our study from a single integrated health system with comprehensive clinical documentation and follow up, allowed a detailed assessment of pre-and post ESRD transition outcomes that are likely to be captured without ascertainment bias or information gaps.

\section{Potential Limitations}

Our study population may not reflect the experience of all individuals who start ESRD treatment given the fact that our cohort was selected based on CKD patients who were relatively stable, with 2 eGFR measurements 90 or more days apart. Thus, patients with normal baseline renal function who abruptly transitioned to ESRD were not included in our study. Catheter use and inpatient ESRD transitions were lower in our cohort than what has been described for the United States ESRD population overall[1]. This may suggest that they may have been managed differently and perhaps were more "prepared" for ESRD transition. While we evaluated race/ethnicity, sex, and age on our outcome, we did not explore more granular patient information including socioeconomic and sociodemographic backgrounds. We also did not have reliable information on lifestyle including smoking and substance abuse. In addition, information on dialysis adherence or missed dialysis during the observation window was not available. Another consideration is that within the Kaiser Permanente integrated health system, there is more standardizations in care among the CKD population. CKD specific interventions such as blood pressure control, anemia management, CKD-MBD management, and CKD related patient education are accessible to all CKD patients. Moreover, KPSC has an internal CKD registry that identifies patients and gives feedback to providers on management. Similar mechanisms are in place for other chronic conditions such as hypertension and patient safety nets[34,35]. Thus, our findings may not reflect the heterogeneity in practice patterns and treatment environments found in pooled cohorts.

Another potential limitation of our study is the lack of information on cause of death. Cardiovascular events are high in the early ESRD period and are a major contributor to ESRD mortality[36]. Given the potential for discrepancies and reliability concerns, we were cautious about solely relying on the Center for Medicare and Medicaid Services (CMS) ESRD death notification form 2746 [37]. We also did not censor patients who switched dialysis modalities or received a renal transplant within the first 6 months. In addition, we did not censor patients that may have left the health plan because the state files would have captured any mortality although, we may have missed deaths among patients who left the health plan and state and then died within 6 months. 


\section{Conclusion}

Among a CKD population who transitioned to ESRD, we observed high mortality immediately after the start of dialysis especially among HD patients who transitioned with a catheter. Patients who transitioned in an inpatient setting, who had higher eGFR at transition, and who were recently diagnosed with AKI also had higher early mortality risk. This information may lead to more effective management strategies and inform shared decision making.

\section{Supplementary Material}

Refer to Web version on PubMed Central for supplementary material.

\section{Acknowledgments}

The authors would like to thank Joanie Chung and David Yi for their work on programming and data extraction for this study. The authors also would like to thank Jose Pio for his literature support and administrative assistance on this study. Finally, we would like to thank and acknowledge the members and patients of KPSC who are the source for our findings and the foundation for why we perform research at KPSC. The results presented in this paper have not been published previously in whole or part, except in abstract format.

Financial Support and Disclosure: This study was funded by 5U01DK102163 from the National Institute of Health (NIH) to CPK and KKZ. This study was also supported by the Kaiser Permanente Southern California Clinician Investigator Award (JJS)

\section{References}

1. Saran R, Robinson B, Abbott KC, Agodoa LY, Ayanian J, Bragg-Gresham J, Balkrishnan R, Chen JL, Cope E, Eggers PW, Gillen D, Gipson D, Hailpern SM, Hall YN, Han Y, He K, Herman W, Heung M, Hutton D, Jacobsen SJ, Kalantar-Zadeh K, Kovesdy CP, Li Y, Lu Y, Molnar MZ, Morgenstern H, Nallamothu B, Nguyen DV, O'Hare AM, Obi Y, Plattner B, Pisoni R, Port FK, Rao P, Ravel V, Rhee CM, Sakhuja A, Schaubel DE, Selewski DT, Sim JJ, Song P, Streja E, Kurella Tamura M, Tentori F, White S, Woodside K, Hirth RA, Shahinian V. US Renal Data System 2016 Annual Data Report: Epidemiology of Kidney Disease in the United States. American journal of kidney diseases: the official journal of the National Kidney Foundation. 2017; 69(3S1):A7-A8. DOI: 10.1053/j.ajkd.2016.12.004 [PubMed: 28236831]

2. Foley RN, Chen SC, Solid CA, Gilbertson DT, Collins AJ. Early mortality in patients starting dialysis appears to go unregistered. Kidney Int. 2014; 86(2):392-398. DOI: 10.1038/ki.2014.15 [PubMed: 24522495]

3. Chan KE, Maddux FW, Tolkoff-Rubin N, Karumanchi SA, Thadhani R, Hakim RM. Early outcomes among those initiating chronic dialysis in the United States. Clin J Am Soc Nephrol. 2011; 6(11): 2642-2649. DOI: 10.2215/CJN.03680411 [PubMed: 21959599]

4. Robinson BM, Zhang J, Morgenstern H, Bradbury BD, Ng LJ, McCullough KP, Gillespie BW, Hakim R, Rayner H, Fort J, Akizawa T, Tentori F, Pisoni RL. Worldwide, mortality risk is high soon after initiation of hemodialysis. Kidney International. 85(1):158-165. DOI: 10.1038/ki.2013.252

5. Sladoje-Martinovic B, Mikolasevic I, Bubic I, Racki S, Orlic L. Survival of chronic hemodialysis patients over 80 years of age. Clinical interventions in aging. 2014; 9:689-696. DOI: 10.2147/ CIA.S58976 [PubMed: 24790421]

6. Bradbury BD, Fissell RB, Albert JM, Anthony MS, Critchlow CW, Pisoni RL, Port FK, Gillespie BW. Predictors of Early Mortality among Incident US Hemodialysis Patients in the Dialysis Outcomes and Practice Patterns Study (DOPPS). Clinical Journal of the American Society of Nephrology. 2007; 2(1):89-99. DOI: 10.2215/cjn.01170905 [PubMed: 17699392]

7. Hwang SJ, Yang WC, Lin MY, Mau LW, Chen HC, Taiwan Society of N. Impact of the clinical conditions at dialysis initiation on mortality in incident haemodialysis patients: a national cohort study in Taiwan. Nephrology, dialysis, transplantation: official publication of the European Dialysis 
and Transplant Association - European Renal Association. 2010; 25(8):2616-2624. DOI: 10.1093/ndt/gfq308

8. Lukowsky LR, Kheifets L, Arah OA, Nissenson AR, Kalantar-Zadeh K. Patterns and predictors of early mortality in incident hemodialysis patients: new insights. Am J Nephrol. 35(6):548-558. doi: 000338673 [pii]. DOI: $10.1159 / 000338673$

9. Wick JP, Turin TC, Faris PD, MacRae JM, Weaver RG, Tonelli M, Manns BJ, Hemmelgarn BR. A Clinical Risk Prediction Tool for 6-Month Mortality After Dialysis Initiation Among Older Adults. American journal of kidney diseases: the official journal of the National Kidney Foundation. 2016; doi: $10.1053 /$ j.ajkd.2016.08.035

10. 2020 HP. (Accessed 1/30/2017) https://www.healthypeople.gov/2020/topics-objectives/topic/ chronic-kidney-disease/objectives

11. USRDS. (Accessed 1/30/2017) https://www.usrds.org/2016/view/v1_08.aspx

12. Lash JP, Go AS, Appel LJ, He J, Ojo A, Rahman M, Townsend RR, Xie D, Cifelli D, Cohan J, Fink JC, Fischer MJ, Gadegbeku C, Hamm LL, Kusek JW, Landis JR, Narva A, Robinson N, Teal V, Feldman HI, Chronic Renal Insufficiency Cohort Study G. Chronic Renal Insufficiency Cohort (CRIC) Study: baseline characteristics and associations with kidney function. Clin J Am Soc Nephrol. 2009; 4(8):1302-1311. DOI: 10.2215/CJN.00070109 [PubMed: 19541818]

13. Mariani L, Stengel B, Combe C, Massy ZA, Reichel H, Fliser D, Pecoits-Filho R, Lopes AA, Yamagata K, Wada T, Wong MM, Speyer E, Port FK, Pisoni RL, Robinson BM. The CKD Outcomes and Practice Patterns Study (CKDopps): Rationale and Methods. American journal of kidney diseases: the official journal of the National Kidney Foundation. 2016; 68(3):402-413. DOI: 10.1053/j.ajkd.2016.03.414 [PubMed: 27113505]

14. Kalantar-Zadeh K, Kovesdy CP, Streja E, Rhee CM, Soohoo M, Chen JL, Molnar MZ, Obi Y, Gillen D, Nguyen DV, Norris KC, Sim JJ, Jacobsen SS. Transition of care from pre-dialysis prelude to renal replacement therapy: the blueprints of emerging research in advanced chronic kidney disease. Nephrology, dialysis, transplantation: official publication of the European Dialysis and Transplant Association - European Renal Association. 2017; doi: 10.1093/ndt/gfw357

15. Levey AS, de Jong PE, Coresh J, El Nahas M, Astor BC, Matsushita K, Gansevoort RT, Kasiske BL, Eckardt KU. The definition, classification, and prognosis of chronic kidney disease: a KDIGO Controversies Conference report. Kidney Int. 2011; 80(1):17-28. DOI: 10.1038/ki.2010.483 [PubMed: 21150873]

16. Levey AS, Stevens LA, Schmid CH, Zhang YL, Castro AF 3rd, Feldman HI, Kusek JW, Eggers P, Van Lente F, Greene T, Coresh J, Ckd EPI. A new equation to estimate glomerular filtration rate. Annals of internal medicine. 2009; 150(9):604-612. [PubMed: 19414839]

17. Rutkowski M, Mann W, Derose S, Selevan D, Pascual N, Diesto J, Crooks P. Implementing KDOQI CKD definition and staging guidelines in Southern California Kaiser Permanente. American journal of kidney diseases: the official journal of the National Kidney Foundation. 2009; 53(3 Suppl 3):S86-99. DOI: 10.1053/j.ajkd.2008.07.052 [PubMed: 19231766]

18. Rivara MB, Chen CH, Nair A, Cobb D, Himmelfarb J, Mehrotra R. Indication for Dialysis Initiation and Mortality in Patients With Chronic Kidney Failure: A Retrospective Cohort Study. American journal of kidney diseases: the official journal of the National Kidney Foundation. 2016; doi: 10.1053/j.ajkd.2016.06.024

19. Naimark DM, Grams ME, Matsushita K, Black C, Drion I, Fox CS, Inker LA, Ishani A, Jee SH, Kitamura A, Lea JP, Nally J, Peralta CA, Rothenbacher D, Ryu S, Tonelli M, Yatsuya H, Coresh J, Gansevoort RT, Warnock DG, Woodward M, de Jong PE, Consortium CKDP. Past Decline Versus Current eGFR and Subsequent Mortality Risk. Journal of the American Society of Nephrology: JASN. 2016; 27(8):2456-2466. DOI: 10.1681/ASN.2015060688 [PubMed: 26657865]

20. Xue JL, Dahl D, Ebben JP, Collins AJ. The association of initial hemodialysis access type with mortality outcomes in elderly Medicare ESRD patients. American journal of kidney diseases: the official journal of the National Kidney Foundation. 2003; 42(5):1013-1019. [PubMed: 14582045]

21. Fischer MJ, Stroupe KT, Kaufman JS, O’Hare AM, Browning MM, Sohn MW, Huo Z, Hynes DM. Predialysis nephrology care and dialysis-related health outcomes among older adults initiating dialysis. BMC nephrology. 2016; 17(1):103.doi: 10.1186/s12882-016-0324-5 [PubMed: 27473684] 
22. Cooper BA, Branley P, Bulfone L, Collins JF, Craig JC, Fraenkel MB, Harris A, Johnson DW, Kesselhut J, Li JJ, Luxton G, Pilmore A, Tiller DJ, Harris DC, Pollock CA. A Randomized, Controlled Trial of Early versus Late Initiation of Dialysis. New England Journal of Medicine. 2010; 363(7):609-619. DOI: 10.1056/NEJMoa1000552 [PubMed: 20581422]

23. Yamagata K, Nakai S, Iseki K, Tsubakihara Y, Committee of Renal Data Registry of the Japanese Society for Dialysis T. Late dialysis start did not affect long-term outcome in Japanese dialysis patients: long-term prognosis from Japanese Society for [corrected] Dialysis Therapy Registry. Therapeutic apheresis and dialysis: official peer-reviewed journal of the International Society for Apheresis, the Japanese Society for Apheresis, the Japanese Society for Dialysis Therapy. 2012; 16(2):111-120. DOI: 10.1111/j.1744-9987.2011.01052.x

24. Wright S, Klausner D, Baird B, Williams ME, Steinman T, Tang H, Ragasa R, GoldfarbRumyantzev AS. Timing of Dialysis Initiation and Survival in ESRD. Clinical Journal of the American Society of Nephrology: CJASN. 2010; 5(10):1828-1835. DOI: 10.2215/CJN.06230909 [PubMed: 20634325]

25. Dhingra RK, Young EW, Hulbert-Shearon TE, Leavey SF, Port FK. Type of vascular access and mortality in U.S. hemodialysis patients. Kidney International. 2001; 60(4):1443-1451. doi: https:// doi.org/10.1046/j.1523-1755.2001.00947.x. [PubMed: 11576358]

26. Moist LM, Trpeski L, Na Y, Lok CE. Increased Hemodialysis Catheter Use in Canada and Associated Mortality Risk: Data from the Canadian Organ Replacement Registry 2001-2004. Clinical Journal of the American Society of Nephrology. 2008; 3(6):1726-1732. DOI: 10.2215/ cjn.01240308 [PubMed: 18922993]

27. Jaar BG, Coresh J, Plantinga LC, Fink NE, Klag MJ, Levey AS, Levin NW, Sadler JH, Kliger A, Powe NR. Comparing the risk for death with peritoneal dialysis and hemodialysis in a national cohort of patients with chronic kidney disease. Annals of internal medicine. 2005; 143(3):174183. [PubMed: 16061915]

28. Ganesh SK, Hulbert-Shearon T, Port FK, Eagle K, Stack AG. Mortality differences by dialysis modality among incident ESRD patients with and without coronary artery disease. Journal of the American Society of Nephrology: JASN. 2003; 14(2):415-424. [PubMed: 12538742]

29. Vonesh EF, Snyder JJ, Foley RN, Collins AJ. The differential impact of risk factors on mortality in hemodialysis and peritoneal dialysis. Kidney Int. 2004; 66(6):2389-2401. DOI: 10.1111/j. 1523-1755.2004.66028.x [PubMed: 15569331]

30. Thamer M, Kaufman JS, Zhang Y, Zhang Q, Cotter DJ, Bang H. Predicting Early Death Among Elderly Dialysis Patients: Development and Validation of a Risk Score to Assist Shared Decision Making for Dialysis Initiation. American journal of kidney diseases: the official journal of the National Kidney Foundation. 66(6):1024-1032. doi:S0272-6386(15)00838-0 [pii]. DOI: 10.1053/ j.ajkd.2015.05.014

31. Verberne WR, Geers AB, Jellema WT, Vincent HH, van Delden JJ, Bos WJ. Comparative Survival among Older Adults with Advanced Kidney Disease Managed Conservatively Versus with Dialysis. Clin J Am Soc Nephrol. 2016; 11(4):633-640. DOI: 10.2215/CJN.07510715 [PubMed: 26988748]

32. Foote C, Ninomiya T, Gallagher M, Perkovic V, Cass A, McDonald SP, Jardine M. Survival of elderly dialysis patients is predicted by both patient and practice characteristics. Nephrology, dialysis, transplantation: official publication of the European Dialysis and Transplant Association European Renal Association. 2012; 27(9):3581-3587. DOI: 10.1093/ndt/gfs096

33. Jha V, Garcia-Garcia G, Iseki K, Li Z, Naicker S, Plattner B, Saran R, Wang AY, Yang CW. Chronic kidney disease: global dimension and perspectives. Lancet. 2013; 382(9888):260-272. DOI: 10.1016/S0140-6736(13)60687-X [PubMed: 23727169]

34. Sim JJ, Rutkowski MP, Selevan DC, Batech M, Timmins R, Slezak JM, Jacobsen SJ, Kanter MH. Kaiser Permanente Creatinine Safety Program: A Mechanism to Ensure Widespread Detection and Care for Chronic Kidney Disease. Am J Med. 128(11):1204-1211 e1201. doi:S0002-9343(15)00536-7 [pii]. DOI: 10.1016/j.amjmed.2015.05.037

35. Sim JJ, Handler J, Jacobsen SJ, Kanter MH. Systemic implementation strategies to improve hypertension: the Kaiser Permanente Southern California experience. Can J Cardiol. 30(5):544552. doi:S0828-282X(14)00007-5 [pii]. DOI: 10.1016/j.cjca.2014.01.003 
36. Eckardt KU, Gillespie IA, Kronenberg F, Richards S, Stenvinkel P, Anker SD, Wheeler DC, de Francisco AL, Marcelli D, Froissart M, Floege J, Committee AROS. High cardiovascular event rates occur within the first weeks of starting hemodialysis. Kidney Int. 2015; 88(5):1117-1125. DOI: 10.1038/ki.2015.117 [PubMed: 25923984]

37. Rocco MV, Yan G, Gassman J, Lewis JB, Ornt D, Weiss B, Levey AS, Hemodialysis Study G. Comparison of causes of death using HEMO Study and HCFA end-stage renal disease death notification classification systems. The National Institutes of Health-funded Hemodialysis. Health Care Financing Administration. American journal of kidney diseases: the official journal of the National Kidney Foundation. 2002; 39(1):146-153. [PubMed: 11774113] 


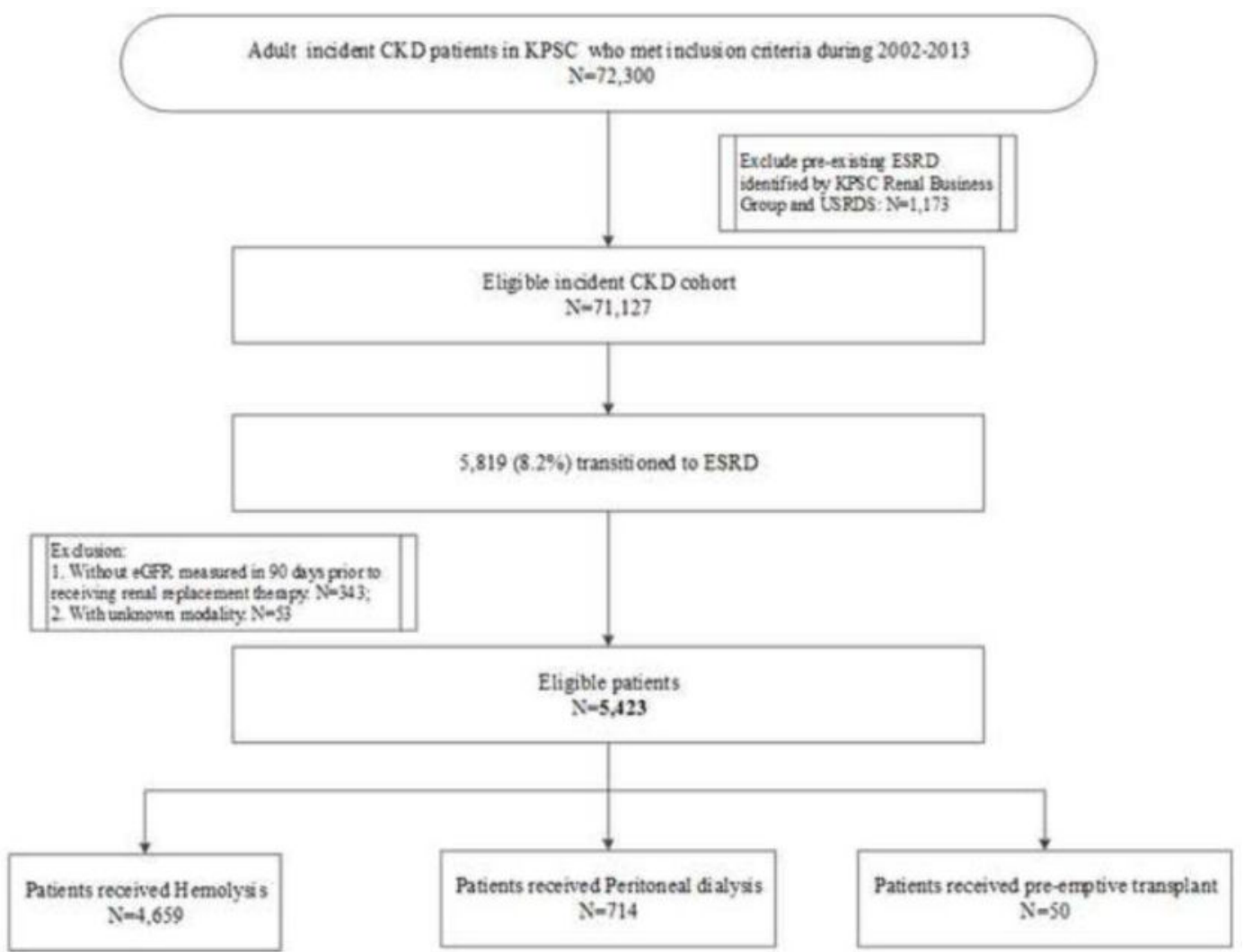

Figure 1.

Among a total of 71,127 individuals (between 2002-2013) who were identified with CKD, $5,819(8.2 \%)$ transitioned to ESRD. The study cohort was comprised of 5,373 CKD patients who transitioned to ESRD, had a documented eGFR within 90 days pretransition, and had an ESRD modality identified. 

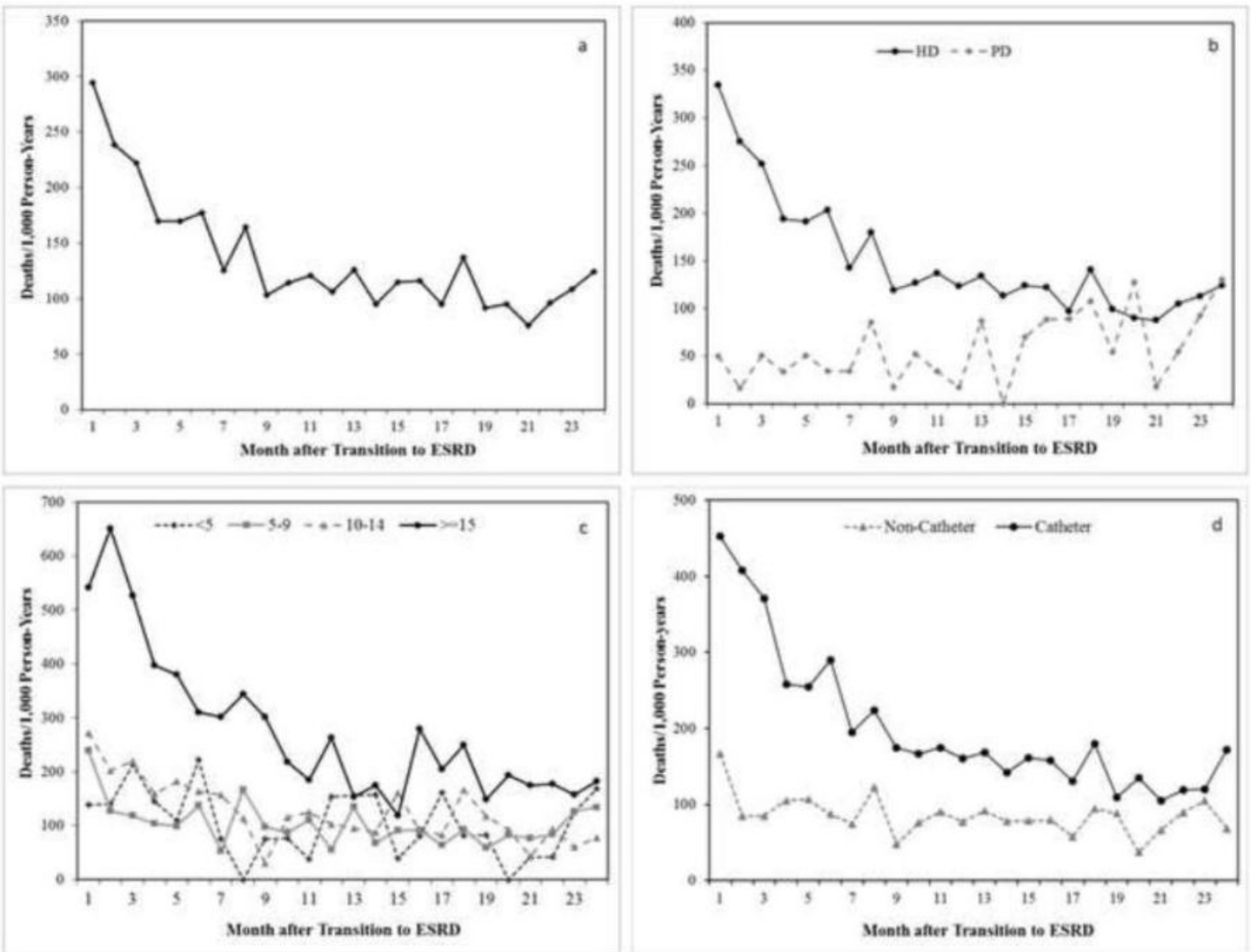

Figure 2.

Monthly mortality rates up to 24 months of follow-up are reported in deaths per 100 personyears. a) Mortality rates for the entire ESRD transition population ( $\mathrm{N}=5,373)$. b) Mortality rates for hemodialysis with catheter(HD-catheter), hemodialysis with AVF/AVG (HD-AVF/ AVG) and peritoneal dialysis (PD) populations separately not including transplant. c) Mortality rates of the entire study cohort categorized by eGFR at transition $(<5,5-9,10-14$, and $\geq 15 \mathrm{ml} / \mathrm{min} / 1.73 \mathrm{~m}^{2}$ ). $\mathrm{d}$ Mortality rates of the entire study cohort categorized by age $(<60,60-69,70-79$, and $\geq 80)$. 


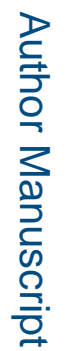

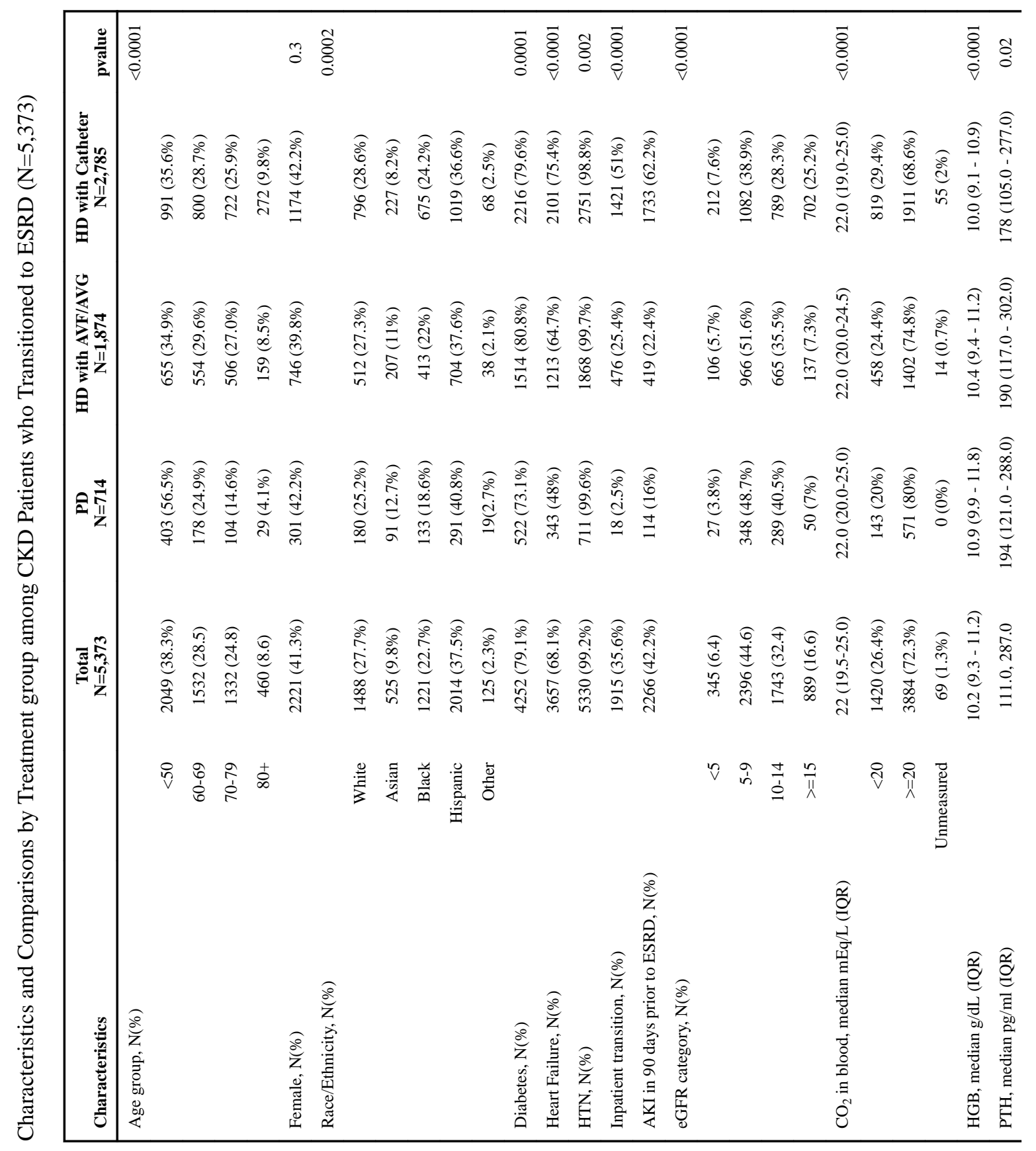

Int Urol Nephrol. Author manuscript; available in PMC 2019 May 01. 


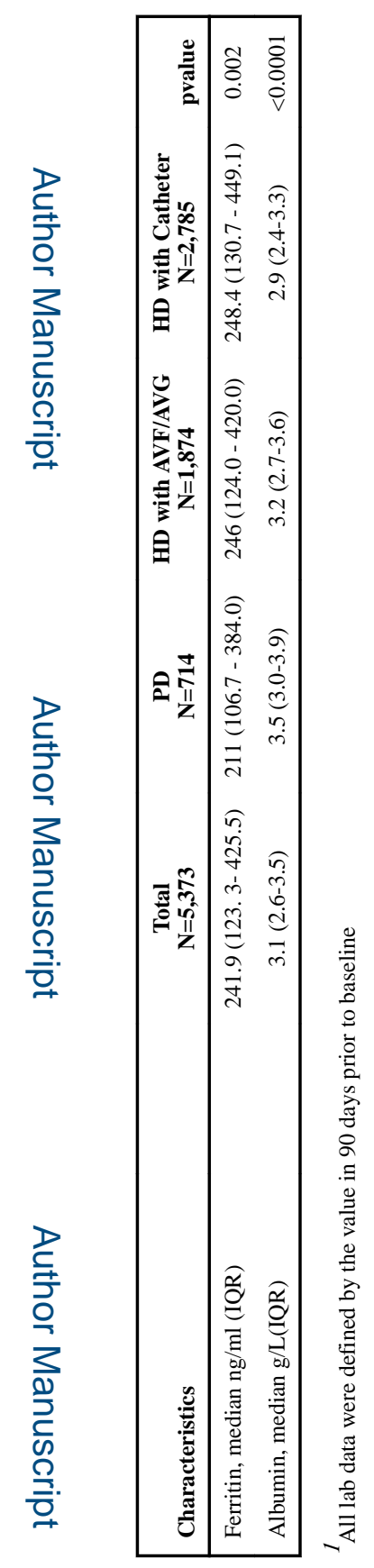


Table 2

Hazard Ratios for 6-Month Mortality among incident ESRD patients by Treatment Group

\begin{tabular}{|c|c|c|c|c|}
\hline & & HR $(95 \% \mathrm{CI})^{1}$ & HR $(95 \% \mathrm{CI})^{2}$ & HR $(95 \% \mathrm{CI})^{3}$ \\
\hline \multicolumn{5}{|l|}{ Modality } \\
\hline & PD & & Reference & \\
\hline & HD with AVF/AVG & $2.65(1.51-4.64)$ & $2.10(1.20-3.68)$ & $1.87(1.06-3.30)$ \\
\hline & HD with Catheter & $8.55(5.02-14.55)$ & $6.65(3.90-11.34)$ & $3.77(2.17-6.57)$ \\
\hline
\end{tabular}

${ }^{1}$ Unadjusted

${ }^{2}$ Adjusted for age, sex, and race/ethnicity

3

${ }^{3}$ Adjusted for age, sex, race/ethnicity, eGFR prior to transition, diabetes, heart failure, acute kidney injury, inpatient transition, bicarbonate level, and albumin. 